\title{
Harnessing creative risk sharing
}

Cash constraints and a heightened perception of risk in the pharmaceutical industry are contributing to a deal-making environment in which atypical deal structures based on the creative sharing of value and risk are being explored to improve on traditional, simple structures that may financially expose one party disproportionately. Through the analysis of deals with more advanced structures in the PharmaDeals database over the past 18 months, we have identified several risk-sharing features that have generated successful licensing and acquisition agreements in situations in which the risks were probably considered too high for traditional types of deals.

The first such feature has been the evolution of option-based agreements (Nature Rev. Drug Discov. 9, 422; 2010). A key example is the recent deal between GlaxoSmithKline (GSK) and Isis Pharmaceuticals (31 March 2010) for the potential licensing of compounds originating from the antisense discovery platform of Isis. In this deal, the US\$35 million upfront payment from GSK covers six programmes with an option to license later, but GSK also committed to proof-of-concept milestone success payments of $\$ 20$ million per programme before any licensing decision. This is a considerable step beyond what standard option agreements offer, although GSK also retains the full freedom to license or abandon the compounds at the proof-of-concept stage.

The second feature we identified is company acquisitions in which the valuation of the assets involved depends on the results of ongoing clinical trials. This type of deal has an optional success-based component that allows the acquirer to lower their risk and allows the target company to obtain a higher price. An example is provided by the deal between Cephalon and Ception Therapeutics (13 January 2009). Cephalon paid $\$ 100$ million upfront that served as an option, but not a commitment, to purchase all the outstanding stock of Ception. The option to purchase could occur at any time before the expiration of a specific time period after the receipt of the final report of a Phase Ilb/III trial of Ception's lead drug reslizumab, for the treatment of paediatric eosinophilic oesophagitis (Nature Rev. Drug Discov. 8, 185; 2009). Just over a year later, the receipt of positive data from a second Phase II trial of reslizumab in adults with eosinophilic asthma led to Cephalon exercising the option and paying an additional $\$ 250$ million to fully purchase Ception.

The third feature we identified is the use of complex equity investments alongside a licensing structure, which is illustrated by a deal between Ipsen and Inspiration (21 January 2010) to create a combined haemophilia franchise. As part of the deal, Ipsen exclusively licensed its recombinant porcine factor VIII product candidate OBI-1, for which Phase III testing was scheduled to commence in 2010, to Inspiration for $\$ 50$ million in convertible notes and $27.5 \%$ potential royalties on future sales. In addition, Ipsen made an upfront investment of $\$ 85$ million in a new class of preferred stock (constituting $20 \%$ of Inspiration's fully diluted equity) and received a seat on the board of its partner. Moreover, milestone payments of up to $\$ 174$ million would potentially be paid by Ipsen based on the successful development of $\mathrm{OBI}-1$ and Inspiration's recombinant factor IX product IB1001, for which Phase III testing was also scheduled to commence in 2010. For each payment, Ipsen would receive further notes convertible into equity in Inspiration, which would correspond to owning $47 \%$ of Inspiration if all payments were made. Finally, certain triggering events would also allow Ipsen the right to fully acquire its partner. Overall, this provides a strong illustration of a deal in which each party flexibly and effectively used their financial or non-financial assets to make the deal happen.

Tibor Papp, M.D., Ph.D., is Head of Corporate Advisory at PharmaVentures Ltd, Florey House, Oxford Science Park, Oxford OX4 4GP, UK e-mail: tibor.papp@pharmaventures.com The author declares no competing financial interests. 